* Mestrando em Teorias Jurídicas Contemporâneas pelo Programa de Pós-Graduação em Direito da Universidade Federal do Rio de Janeiro. E-mail: henriquer angelc@gmail.com

** Professor Adjunto e ViceDiretor da Faculdade Nacional de Direito e Professor Permanente do Programa de Pós-Graduação em Direito da Universidade $\mathrm{Fe}$ deral do Rio de Janeiro. Diretor do Centro de Pesquisa e Documentação da Ordem dos Advogados do Brasil, Subseção do Rio de Janeiro. Bolsista de Produtividade em Pesquisa pelo Conselho Nacional de Desenvolvimento Científico e Tecnológico. E-mail: bolonhacarlos@gmail.com *** Professor do Curso de LL.M em Direito Tributário da Fundação Getúlio Vargas, do Curso de Especialização em Direito Financeiro e Tributário da Universidade Federal Fluminense e do Curso de Direito Tributário da Escola Superior de Administração Fazendária. Doutorando em Finanças Públicas, Tributação e Desenvolvimento pelo Programa de Pós-Graduação em Direito da Faculdade de Direito da Universidade do Estado do Rio de Janeiro. Mestre em Teorias Jurídicas Contemporâneas pelo Programa de Pós-Graduação em Direito da Universidade Federal do Rio de Janeiro. Auditor Fiscal da Secretaria da Receita Federal do Brasil. E-mail: agsepulveda@ig.com.br

\section{Cortes constitucionais e instrumentalização da legitimidade $^{1}$}

\author{
COnSTITUTIONAL COURTS AND \\ INSTRUMENTALIZATION OF LEGITIMACY \\ * Henrique Rangel \\ ** Carlos Bolonha \\ *** Antonio Sepulveda
}

Resumo: As instituições democráticas atendem ao seu papel constitucional no interior da atividade política do Estado. As Cortes Constitucionais representam as instituições que melhor promovem esta função. O presente artigo busca investigar, em particular, a Corte Constitucional brasileira em seus comportamentos deliberativos, dialógicos e sistêmicos, focando no que se chama de instrumentalização da legitimidade. Acreditase que estes mecanismos se apresentam, pelo menos, em duas formas: (i) por mecanismos de inclusão-participativa; e (ii) por mecanismos dialógicos institucionais. Ambos os canais permitem as Cortes alcançarem uma posição de destaque na definição de parâmetros deliberativos que, sustenta-se, são pressupostos para um compromisso institucional cooperativo. O objetivo deste artigo é verificar as capacidades institucionais da Corte brasileira no atendimento deste papel ao aplicar mecanismos de instrumentalização da legitimidade, e analisar a contribuição destes para a construção de parâmetros deliberativos.

Palavras-chave: Cortes Constitucionais; Teoria Deliberativa; Capacidades Institucionais; Diálogos Institucionais; Instrumentalização da Legitimidade.

${ }^{1}$ Este artigo foi elaborado no âmbito do Laboratório de Estudos Teóricos e Analíticos sobre o Comportamento das Instituições (LETACI), vinculado à Faculdade Nacional de Direito (FND) e ao Programa de Pós-Graduação em Direito (PPGD) da Universidade Federal do Rio de Janeiro (UFRJ), financiado pelo Conselho Nacional de Desenvolvimento Científico e Tecnológico (CNPq), no âmbito do Edital Universal no 14/2013, e pela Fundação Carlos Chagas Filho de Amparo à Pesquisa do Estado do Rio de Janeiro (FAPERJ), no âmbito das concorrências do Auxílio à Pesquisa, APQ-1, 2013, e do Edital no 41/2013, do Programa de Apoio a Grupos Emergentes de Pesquisa no Estado do Rio de Janeiro. 
Abstract: The democratic institutions attempt their constitutional role inside the political activity of the State. The Constitutional Courts represent the institutions whom had better promote that functions. This paper looks for investigate the Brazilian, in their deliberative, dialogic and systemic behavior, focusing mainly in what we call instrumentalization of legitimacy. We believe these mechanisms are presented by at least two forms: (i) by participativeinclusion mechanisms; and (ii) by institutional dialogic mechanisms. Both channels allow the Courts reach an award position on the definition of deliberative parameters which, we urges, are presupposed to an institutional cooperative commitment. The objective of this article is to verify the institutional capacities of some Courts to attempt this role applying instrumentalization of legitimacy mechanisms, and analyze its contribution to the construction of deliberative parameters.

Keywords: Constitutional Courts; Deliberation Theory; Institutional Capacities; Institutional Dialogues; Instrumentalization of Legitimacy. 


\section{INTRODUÇÃO}

As instituições democráticas atendem ao seu papel constitucional em uma atividade política de Estado. ${ }^{1}$ As Cortes Constitucionais são aquelas que melhor promovem esta função. Este estudo investiga, em particular, os mecanismos da Corte Constitucional brasileira na garantia da definição de parâmetros deliberativos, eliminando, porém, a possibilidade de caracterização de uma supremacia judicial. ${ }^{2}$

No Brasil, há exemplos como o amicus curiae e as audiências públicas. Além do mais, uma atividade institucional, associada a compromissos cooperativos, pressupõe a elaboração de parâmetros deliberativos para amparar seu déficit de legitimidade. Por um lado, pode-se dizer que as Cortes atuando em questões políticas de elevado desacordo sem o suporte de instrumentos que auxiliem este déficit de legitimidade é mais suscetível de desgaste perante a população e as demais instituições. Por outro lado, a Corte que responde ao crescimento da demanda social para a efetivação de direitos básicos e para a

\footnotetext{
"O termo "instituições democráticas" utilizado no presente artigo não se limita às instituições representativas do sistema político. Esta, na verdade, parece limitar a noção de democracia a seu aspecto representativo, quando outras situações como a legitimidade também concorrem na atribuição de seu sentido. Por esta razão, as Cortes Constitucionais também são integradas a esta terminologia, uma vez que, mesmo sem representação popular, desempenham funções constitucionalmente definidas e promovendo direitos e garantias a seus jurisdicionados. O critério determinante para a compreensão de uma instituição como democrática ou não, portanto, é a promoção de princípios de justiça em sua atividade (BOLONHA; RANGEL; ALMEIDA, 2011).

2 Tratar o Supremo Tribunal Federal (STF) como uma Corte Constitucional não é um posicionamento acadêmico aceito de maneira unânime. O caráter híbrido das funções exercidas por esse Tribunal conduzem juristas a discutir acerca de sua configuração enquanto Suprema Corte ou Corte Constitucional, respectivamente concentradas nas atividades de última instância recursal e de controle de constitucionalidade. Uma das referências mais prestigiadas no assunto é a obra de Louis Fovoreu, em que estabelece como critério definidor de uma Corte Constitucional o desempenho de função especial e exclusivamente de natureza contenciosa constitucional. (FAVOREU, 2004). Esse não é único critério oferecido no meio acadêmico, embora altamente influente. Sobretudo a partir do modelo europeu de controle de constitucionalidade, é possível sistematizar algumas características marcantes dos autênticos modelos de Tribunal Constitucional, como fez José de Albuquerque Rocha. De acordo com esse autor, cinco critérios poderiam ser utilizados para esta finalidade: (i) estatuto constitucional, que indica sua previsão na Constituição; (ii) designação por critérios político-democráticos, devendo a composição da Corte ser definida por eleição de categorias profissionais do direito, como magistratura, sociedade civil, Ministério Público e Poder Executivo; (iii) mandato fixo e improrrogável; (iv) incompatibilidade, impedindo a acumulação do membro do Tribunal com diversa função, sobretudo política; e (v) competência, centralidade no exercício do controle de constitucionalidade. (ROCHA, 1995). Em verdade, o STF é uma Corte que não se enquadra, definitivamente, nos critérios "ii" e "iii", sendo extremamente controvertido se atenderia também ao critério "v". Isso ocorre porque o STF reúne competências amplas, pelo menos, de controle de constitucionalidade, de última instância recursal - além de instância recursal originária em determinadas hipóteses -, de dissídios federativos e de foro por prerrogativa de função. Além dessa amplitude, pesquisas empíricas têm evidenciado a predominância do caráter de Corte recursal
} 
tomada de decisões essenciais, ao mesmo tempo em que se abre ao diálogo com a população ou demais instituições, pode observar o aumento do reconhecimento de sua legitimidade.

É necessário verificar a importância e a aptidão das Cortes em atender a esta função analisando suas capacidades institucionais. Também é necessário identificar estes mecanismos de instrumentalização da legitimidade em um sistema deliberativo democrático e seu exercício pelo guardião da Constituição. Considerando o crescimento da importância destes novos mecanismos na jurisdição constitucional, algumas instituições estrangeiras podem auxiliar na sua compreensão, a exemplo das Cortes norte-americana e canadense. A estabilização da ordem constitucional e de parâmetros políticos, assim como a promoção de um sistema de direitos, através das Cortes Constitucionais são situações que, em contrapartida, podem conduzir a dificuldades no plano democrático, resultando em significativos desgastes.

O objeto central deste trabalho é o fenômeno responsável por compensar este déficit democrático das Cortes Constitucionais. Acredita-se que estes mecanismos se apresentem, pelo menos, através de duas formas distintas: por mecanismos de inclusão-participativa e por mecanismos de atividade dialógicoinstitucional.

\section{O JUDICIAL REVIEW EA CONQUISTA HISTÓRICA DE SEUS CONTORNOS POLÍTICOS}

$\mathrm{Na}$ teoria constitucional norte-americana, tornou-se um desafio, para qualquer estudioso, apresentar sistematicamente os desdobramentos teóricos sobre a atividade da Corte Constitucional. Criaram-se perspectivas de profunda

do STF do ponto-de-vista quantitativo, fortalecendo sua semelhança com o perfil de Corte Suprema. (FALCÃO; HARTMANN; CHAVES, 2014). Atualmente, há um Projeto de Emenda à Constituição - PEC $n^{\circ}$ 275/2013 -, que pretende alterar esse perfil do STF, aproximando-o de uma autêntica Corte Constitucional e transferindo parcela significativa de sua atuação recursal ao Superior Tribunal de Justiça, o que resultaria em um desenho similar ao português de segregação entre Tribunal Constitucional e Supremo Tribunal de Justiça. Embora o STF não se submeta, com perfeição, aos critérios academicamente firmados para caracterização de uma Corte Constitucional, com especial ênfase à tradição jurisdicional europeia, é inegável que o exercício do contencioso constitucional, no Brasil é desempenhado de maneira exclusiva por essa instituição. O fato de o STF ser quem exerce, no Brasil, o controle de constitucionalidade, considerando que os mecanismos de controle preventivo no interior do Congresso Nacional não têm se desvencilhado da função política precípua dessa instituição, torna problemático retirar, por completo, seu perfil de Corte Constitucional. Por essa razão, sustenta-se que o STF represente um caso de Corte Constitucional inautêntica: apesar de não se submeter aos padrões regulares de caracterização apresentados acima, é a instituição que exerce com centralidade a função de contencioso constitucional no país.

REVISTA DO DIREITO PÚBLICO, Londrina, v.10, n.1, p.171-187, jan./abr.2015 
especificidade para analisar e contribuir para uma atuação criativa do judicial review, discutindo, sobretudo, o status de supremacia judicial.

O judicial review passou por, pelo menos, duas fases marcantes na história constitucional americana. Seu nascimento costuma ser louvado com o caso Marbury v. Madison (1803), mas é necessário observar que o judicial review que se discute hoje não é este. ${ }^{3}$ Tal mecanismo surgiu em um período em que a Corte de Marshall (1801-1835) tentava se livrar das influências político-partidárias sobre sua atividade e sobre suas sucessivas nomeações influenciadas pelo plano de governo dominante. Quando o Chief Justice Marshall defende a impossibilidade desta Corte deliberar sobre matéria que diretamente versa sobre questões políticas, obtém êxito na garantia de um Judiciário independente. Este fato, porém, limitaria a Corte a um reduzido espectro de atuação, mas a criação da doutrina do judicial review sustentou seu status perante os poderes eleitos. Nesta primeira fase, somente a matéria eminentemente jurídica poderia ser alvo de verificação de compatibilidade com a Constituição. O critério utilizado para a distinção entre a legal discretion e a political discretion era o caráter de mutabilidade da matéria. Sendo de maior flutuação no campo político, a controvérsia estaria fora do âmbito de atuação do judicial review. Sendo algo assentado e visto como imutável, poderia a Corte intervir e suprimir a validade do ato. Ressalte-se que o grande fundamento adotado como matéria imutável era a propriedade privada. ${ }^{4}$

Inicialmente, o judicial review, enquanto um instrumento de grande aprovação, ganhou forças e, progressivamente, tornou-se mais recorrente e mais abrangente. Em meados do século XX, porém, a Suprema Corte foi deslocada para o centro das exigências e pressões sociais na reivindicação de prestação de direitos e estabelecimento de parâmetros políticos de deliberação. ${ }^{5}$ Atendendo a estas expectativas, assumiram um verdadeiro papel de protagonista político e deliberativo as Cortes de Warren e de Burger nos Estados Unidos. Nestes períodos, a Suprema Corte assumiu uma responsabilidade política de atuação que transformou em regra o enfrentamento de controvérsias que seriam tipicamente, na origem do judicial review, de political discretion. Desta forma, alguns autores afirmam, a partir desta proeminência política da Corte, um quadro

\footnotetext{
${ }^{3}$ Marbury v. Madison, 5 U.S. 137 (1803).

${ }^{4}$ Sobre este período inicial do judicial review e suas divisões entre legal e political discretion, (WILLIAM, 2000).

5 Para fins de delimitação do conceito de deliberação, a presente pesquisa adota como seu referencial a obra (BOHMAN, 2000).
} 
de supremacia judicial, correspondente a uma segunda fase do judicial review (GRIFFIN, 2005).

Sendo o centro das atenções e pressões, entretanto, foi inevitável o desgaste do judicial review, ao final do século XX e início do século XXI. O comportamento da Corte tornou-se prudentemente mais contido. As correntes do constrained judicial review, havendo quem o subdivida em constitucionalismo popular, departamentalismo e week form judicial review ${ }^{6}$. No atual debate sobre o judicial review, defende-se, por um lado, um modelo fortemente dialógico (constrained judicial review) e, por outro lado, um modelo de revisão que favoreça a autonomia do Judiciário em matérias de teor mais político (strong judicial review). A autonomia da Corte para integrar ou não outras instituições a esta atividade de maior conteúdo político se tornou o foco da discussão.

É com esta dimensão teórica sustentada pelos juristas norte-americanos, sobre os temas relativos à atividade de sua Corte, que se pode analisar, por exemplo, a atividade do Supremo Tribunal Federal (STF). Atualmente, este apresenta um aparente comportamento que foge do que se entende como strong judicial review, para moldar-se a uma postura constrainted judicial review, valorizando a atuação das outras instituições democráticas. Os polêmicos julgamentos da inconstitucionalidade da Lei do Ficha Limpa (Lei Complementar nº 135/2010), não a aplicando às eleições imediatamente após sua publicação, e da extradição do italiano Cesare Battisti, apreciando-a como legal, mas decidindo que a palavra final caberia ao Presidente da República - que não o extraditou -, mostram uma modulação da atuação no sentido deste comportamento ${ }^{7}$.

\footnotetext{
${ }^{6}$ É o que se apresenta em (SHINAR; HAREL, 2011). Representam a corrente do constitucionalismo popular autores contemporâneos que combatem a capacidade de o Judiciário exercer o controle de constitucionalidade das leis, defendendo um padrão democrático mais estabelecido no princípio majoritário, indo de encontro com a democracia constitucional dworkiniana e seus núcleos de princípios fundamentais de intangibilidade moral individual. Trata-se de autores que rejeitam a noção de "trunfos contra a maioria" do contramajoritarismo atual. Pode-se afirmar que há a defesa de uma espécie de legislature supremacy (TUSHNET, 2006). Para o departamentalismo, o sistema jurídico deve estar aberto para a atuação legislativa, porém, muito claramente definidos os limites do judicial review. Impede-se que haja interferências além de suas próprias competências, criticando uma postura ativista que avance sobre assuntos políticos atribuídos a diverso Poder (THAYER, 1893). Com as teorias do week form judicial review, encontram-se propostas de uma atuação branda, geralmente, apenas como suficiente para a garantia concreta de direitos. É possível citar como um exemplo destes modelos de judicial review, o second look (DIXON, 2011). Alguns entendem certos trabalhos de Mark Tushnet como integrantes desta subdivisão (TUSHNET, 2007).

7 Para o caso Lei do Ficha Limpa, Cf. Recurso Extraordinário nº 633.703, Min. Rel. Gilmar Mendes, 5/04/2011. Para o caso de Cesare Battisti, Cf. Extadição n ${ }^{\circ} 1.085$ e Reclamação Constitucional $n^{\circ}$ 11.243, Min. Rel. Gilmar Mendes, 16/06/2011.
} 


\section{LIMITES INSTITUCIONAIS PARA O JUDICIAL REVIEW}

O debate da teoria constitucional dedicou sua atenção a certos aspectos institucionais dos processos de interpretação da Constituição e das normas infraconstitucionais, bem como seus desdobramentos. ${ }^{8}$ Neste momento, identificaram-se duas questões institucionais: as capacidades institucionais e os efeitos sistêmicos. Esta análise se posiciona criticamente sobre teorias interpretativas, sobretudo, no que tange às chamadas visões perfeccionistas do Poder Judiciário e das Cortes Constitucionais. ${ }^{9}$ Ressalte-se, no entanto, que este enfoque não se restringe apenas ao Judiciário, mas a todas as instituições revestidas de atribuições em uma ordem deliberativa. Isto significa que os processos de deliberação democrática devem considerar, primeiro, quais seriam suas capacidades institucionais para enfrentar a controvérsia e, segundo, quais os resultados sistêmicos que poderiam advir desta decisão. Os resultados pretendidos e as consequências de sua atividade deliberativa dentro de uma ordem institucional dialógica firmam a concepção de efeitos sistêmicos. Estes se preocupam com os resultados que podem recair sobre pessoas, instituições públicas e instituições privadas; o que exige do processo de deliberação um rigor maior na interpretação do caso concreto a partir de suas circunstâncias particulares.

Dessa forma, a partir das críticas encontradas nas chamadas questões institucionais, o processo de deliberação pode ocorrer, legitimamente, de maneira aprofundada e minuciosa, na medida em que for implementada a capacidade da instituição de lidar com o problema e previstas as decorrências sistêmicas de seu desfecho, sobretudo em relação aos seus reflexos sobre outras instituições. Do contrário, não é tão recomendável que a instituição se aventure em interpretações de alto nível de criatividade ou de excepcionalidade. $\mathrm{O}$ afastamento dos termos legais e demais inovações, em que há certa tendência de atuação política, devem ser encargos de instituições dotadas da capacidade correspondente e para situações de reduzidas projeções sistêmicas.

Esta perspectiva institucional traz um posicionamento crítico que, porém, não pretende promover um completo redesenho da ordem constitucional

\footnotetext{
8 As primeiras observações desenvolvidas no que atualmente se chama teoria institucional foram apresentadas por autores, entre outros, como Gillman e Clayton (1999) e Griffin (1999). Porém, esta tradição de pensamento somente se transformou em teoria institucional após o desenvolvimento de pesquisas marcantes como Sunstein e Vermeule (2002) e Levinson e Pildes (2006).

${ }^{9}$ Como fiel representante e defensor do perfeccionismo no direito constitucional (DWORKIN, 1977).
} 
democrática. Muitos dos arranjos institucionais em uma macroesfera já se encontram consolidados e, em que pesem estas duas dificuldades perante a atividade institucional, é mais estratégico criar mecanismos democráticos em um reduzido nível de desenho institucional. ${ }^{10}$ Portanto, mais do que pretender extinguir instituições como o judicial review, parece ser mais apropriado para atender a valores democráticos, como a deliberação, instituir novos mecanismos que superem dificuldades específicas de seu exercício ${ }^{11}$.

\section{MECANISMOS DE INSTRUMENTALIZAÇÃO DA LEGITIMIDADE NO JUDICIAL REVIEW}

Outros estudiosos críticos do pensamento perfeccionista, por sua vez, são surpreendidos por situações excepcionais em que o processo de deliberação explora certos mecanismos e canais que, para o caso em questão, elevam suas capacidades institucionais e melhoram a percepção quanto aos efeitos sistêmicos decorrentes de suas decisões institucionais (LECLAIR, 2003).

Em primeiro lugar, é preciso considerar que o debate sobre perfeccionismo está estritamente ligado a deliberações do Judiciário, uma vez que teve seu início a partir das discussões acerca da legitimidade e do papel do Tribunal em exercer o judicial review. Em segundo lugar, é preciso considerar que algumas críticas sobre o perfeccionismo cuidam de desenvolver uma argumentação tendo por base, unicamente, os juízes nela inseridos. Quando analisam a capacidade institucional da Corte, deixam de considerar que outros atores podem participar do processo deliberativo e do espaço público ali remontado.

Existem institutos, que aqui serão entendidos genericamente como canais de inclusão-participativa, concebidos com a finalidade própria de elevar, por exemplo, as capacidades institucionais do Judiciário. No sistema jurídico

\footnotetext{
${ }^{10} \mathrm{O}$ debate sobre desenho institucional começou a ser desenvolvido com maior vigor a partir da obra coletiva (GOODIN, 1996). Particularmente, há uma concepção de desenhos institucionais em pequena e larga-escalas a que se vincula o presente texto. Os arranjos institucionais seriam aqueles correspondentes aos desenhos em larga-escala, tais como a separação de poderes e o controle de constitucionalidade. Quando se abordam mecanismos institucionais, tais como os de inclusãoparticipativa e de diálogos institucionais ora trabalhados, a referência é diretamente feita aos desenhos institucionais em pequena-escala. Tal classificação é proporcionada por Vermeule (2011).

${ }^{11}$ Ressalte-se, que Adrian Vermeule considera quatro valores democráticos como indispensáveis para a atividade das instituições. Considera-se, especialmente, no presente artigo, a deliberação. "What goals, exactly, are the mechanisms of democracy supposed to serve? How might we judge or not they are successful, and under what conditions? I will suppose mechanisms that advance four core values of democratic constitutionalism: impartiality, accountability, transparency, and deliberation". (VERMEULE, 2011, p. 4) (grifos do autor).
} 
brasileiro, destacam-se, entre eles, (i) o amicus curiae e, mais recentemente, (ii) as audiências públicas.

O primeiro representa uma espécie de manifestação de terceiro no processo judicial em razão de algum interesse próprio sobre a questão em litígio. Há, no Brasil, divergências quanto a sua natureza jurídica; se seria um terceiro interessado ou terceiro não interessado, pela lógica do interesse jurídico no campo processualista. Ao lado destas duas correntes principais de terceiro interessado e terceiro desinteressado, há a posição de Cassio Scarpinella Bueno, concebendo o amicus curiae como um terceiro a quem se atribui interesse institucional - uma vez que está comprometido em auxiliar com a prestação de informações necessárias à resolução do litígio (BUENO, 2008). ${ }^{12} \mathrm{O}$ debate norte-americano, por outro lado, centra-se em outra discussão. Busca entender a lógica do amicus curiae como um verdadeiro "amigo da corte", comprometido

\footnotetext{
${ }^{12}$ A divergência doutrinária parece ter sido amenizada com a publicação da Lei $n^{\circ} 13.105 / 2015$, instituindo o Novo Código de Processo Civil, uma vez que o instituto do amicus curiae passou a receber tratamento legal, diretamente, no título da intervenção de terceiros. Com isso, o amicus curiae estaria atendendo às mesmas premissas dos demais terceiros com interesse jurídico que devessem ou pudessem se manifestar no processo, o que não impede que a discussão acerca do interesse institucional ou meramente jurídico seja mantida. Até então, não havia lei que se referisse diretamente ao termo "amicus curiae" no ordenamento jurídico brasileiro. O que está sendo tratado como inovação do Novo Código de Processo Civil, no entanto, mais parece uma generalização do regramento observado no controle de constitucionalidade, a partir do Regimento Interno do STF. De um lado, o Regimento Interno traz, em suas disposições sobre o Presidente da Corte, sobre o Relator do processo e sobre a existência de Repercussão Geral em Recurso Extraordinário, respectivamente, o seguinte: "Art. 13. São atribuições do Presidente: [...] XVIII - decidir, de forma irrecorrível, sobre a manifestação de terceiros, subscrita por procurador habilitado, em audiências públicas ou em qualquer processo em curso no âmbito da Presidência. [...]; Art. 21. São atribuições do Relator: [...] XVIII - decidir, de forma irrecorrível, sobre a manifestação de terceiros, subscrita por procurador habilitado, em audiências públicas ou nos processos de sua relatoria. [...]; Art. 323. Quando não for caso de inadmissibilidade do recurso por outra razão, o(a) Relator(a) submeterá, por meio eletrônico, aos demais Ministros, cópia de sua manifestação sobre a existência, ou não, de repercussão geral. [...] § $2^{\circ}$ Mediante decisão irrecorrível, poderá o(a) Relator(a) admitir de ofício ou a requerimento, em prazo que fixar, a manifestação de terceiros, subscrita por procurador habilitado, sobre a questão da repercussão geral." De outro lado, o Novo Código de Processo Civil estabelece o seguinte: "Art. 138. O juiz ou o relator, considerando a relevância da matéria, a especificidade do tema objeto da demanda ou a repercussão social da controvérsia, poderá, por decisão irrecorrível, de ofício ou a requerimento das partes ou de quem pretenda manifestar-se, solicitar ou admitir a participação de pessoa natural ou jurídica, órgão ou entidade especializada, com representatividade adequada, no prazo de 15 (quinze) dias de sua intimação." Questões como a irrecorribilidade da decisão que admite ou denega a inserção do amicus curiae no processo, bem como sua possibilidade de admissão de ofício, já eram tratadas de modo pacífico pelo STF, e agora possuem regulamentação no processo civil, em geral. Entretanto, o novo diploma legal tem a oferecer um campo mais abrangente de controvérsias doutrinárias. Por exemplo, o significado de "representatividade adequada" ilustra mais um desafio aos acadêmicos do direito processual, havendo outros conceitos jurídicos que permanecerão indeterminados por algum tempo, tais como "repercussão social da controvérsia". Uma das maiores controvérsias processuais do instituto foi amenizada ao se abordar o amicus curiae no título da intervenção de terceiros, mas o Novo Código de Processo Civil parece ter trazido mais incertezas do que propriamente respostas.
} 
com a solução de um conflito pelo caminho mais justo e devido ao prestar informações relevantes, ou se, em verdade, representa um "amigo da parte", auxiliando a Corte somente na medida em que seus interesses particulares estavam sendo assegurados ${ }^{13}$.

Quanto às audiências públicas, experiência mais recente e ainda pouco explorada ${ }^{14}$, a Lei do Procedimento da Ação Direta de Inconstitucionalidade (ADI) e da Ação Declaratória de Constitucionalidade (ADC), Lei n ${ }^{\circ}$ 9.868/ 1999 , sustenta, em seu art. $9^{\circ}, \S 1^{\circ}$, que o instituto se aplica na necessidade de esclarecimento de matéria ou circunstância de fato ou de notória insuficiência de informações ${ }^{15}$. Seguindo-se rigorosamente o texto, pode-se extrair o sentido de que os entes convidados a se manifestarem em audiência pública atuam com o único e exclusivo interesse de esclarecer a matéria ou circunstância de fato ou prestar informações além das contidas nos autos. Analisando, entretanto, a lógica deste canal inclusivo-participativo, as audiências públicas têm remontado uma figura de espaço público discursivo e argumentativo. ${ }^{16}$ Não há a figura

\footnotetext{
${ }^{13}$ Para Michael Lowman, o amicus curiae, nos EUA, configurava-se mais tendencialmente como um "amigo da parte" (LOWMAN, 1992). Foi este o autor que cunhou o termo litigating amicus para designar a prática assistencialista desse instituto em questões de proteção a interesses próprios em litígios alheios. Após esta pesquisa, outras trataram de avaliar o impacto de tais participações nas decisões da Suprema Corte norte-americana. Entre as mais importantes, (MARRILL; KEARNEY, 2000). Representando desdobramentos desta questão - amigo da parte ou da Corte? - no Brasil, (MEDINA, 2010).

${ }^{14}$ No total, somente 16 audiências públicas foram realizadas pelo STF até abril de 2015, tratando, em ordem cronológica, sobre os seguintes temas: (1) pesquisas com células-tronco embrionárias - ADI $\mathrm{n}^{\circ}$ 3.510; (2) importação de pneus usados - ADPF $\mathrm{n}^{\circ} 101$; (3) interrupção da gestação de fetos anencefálicos - ADPF n ${ }^{\circ} 54$; (4) judicialização do direito à saúde - SL no 47 e outros nove; (5) ações afirmativas no acesso ao ensino superior - ADPF $n^{\circ} 186$ e RE $n^{\circ} 597.285$; (6) proibição da venda de bebidas alcoólicas próxima a rodovias - ADI $n^{\circ} 4.103$; (7) proibição do uso de amianto - ADI $n^{\circ}$ 3.937; (8) marco regulatório para TV por assinatura - ADI $\mathrm{n}^{\circ} 4.679$ e outras duas; (9) campo eletromagnético das linhas de transmissão de energia - RE $\mathrm{n}^{\circ} 627.189$; (10) queimada de canaviais - $\mathrm{RE} \mathrm{n}^{\circ}$ 586.224; (11) regime prisional - $\mathrm{RE} \mathrm{n}^{\circ}$ 641.320; (12) financiamento de campanhas eleitorais - ADI $n^{\circ} 4.650$; (13) publicação de bibliografias não autorizadas - ADI $n^{\circ} 4.815$; (14) Programa "Mais Médicos" - ADI no 5.037 e 5.035; (15) marco regulatório da gestão coletiva de direitos autorais - ADI $n^{\circ} 5.062$ e 5.065; (16) internação hospitalar com diferença de classe na saúde pública - RE $\mathrm{n}^{\circ} 581.488$.

${ }^{15}$ Lei n ${ }^{\circ} 9.868$ de 1999 , art. $9^{\circ}, \S 1^{\circ}$ : "Em caso de necessidade de esclarecimento de matéria ou circunstância de fato ou de notória insuficiência das informações existentes nos autos, poderá o relator requisitar informações adicionais, designar perito ou comissão de peritos para que emita parecer sobre a questão, ou fixar data para, em audiência pública, ouvir depoimentos de pessoas com experiência e autoridade na matéria".

${ }^{16}$ Os instrumentos de inclusão-participativa podem ser aproximados de teorias discursivas como a habermasiana. (HABERMAS, 1996). Tendo em vista que o presente trabalho pretende relacionálos com as questões suscitadas pela teoria institucional, especificamente, e sua influência sobre a legitimidade da Corte Constitucional, optou-se por não promover maiores digressões envolvendo sua adequação discursiva ou sua contribuição ao potencial de racionalidade da ação comunicativa, entre outros aspectos.
} 
institucional de um ente convocado a fornecer subsídios aos juízes para que estes construam, entre si, a decisão adequada. $\mathrm{O}$ decorrer das audiências sugere a tendência de uma situação participativa de deliberação, na qual os atores tratam de se associar a uma das partes litigantes e passam a representar interesses extrajurídicos - políticos, econômicos, filosóficos, teológicos, entre outros - de natureza particular ou relativos a uma categoria ou classe (sendo muito comum, nos Estados Unidos, o emprego do termo bias para tais comportamentos).

O ingresso no processo como amicus curie e a convocação de audiências públicas podem atender, na prática, a distintas finalidades. Sua admissão na Corte Constitucional pode decorrer, desde formalidades legais por haver pertinência temática entre o caso e a atividade do terceiro que pretende se manifestar, até mesmo por motivos de maior relevância. Neste último caso, é possível observar a manifestação de terceiros visando reduzir um déficit informacional, ocasionado pela complexidade da matéria enfrentada ou para legitimar a decisão tomada através da participação de grupos sociais que acompanham o processo. Algumas audiências públicas tiveram a finalidade de preencher esta lacuna informacional da Corte, oferecendo conhecimentos extrajurídicos específicos, como nos casos de pesquisa com células-tronco embrionárias, interrupção da gravidez de fetos anencefálicos e proibição do uso de amianto - pois envolveram aprofundados conhecimentos das ciências da natureza. Outras, por sua vez, serviram para abrir espaço à sociedade como forma de legitimação de sua decisão, como foi o caso das ações afirmativas para acesso ao ensino superior, envolvendo grupos socialmente excluídos como negros, índios e estudantes de escolas públicas por exemplo. Ainda sob este aspecto, as audiências públicas de pesquisa com células-tronco embrionárias e interrupção da gravidez de fetos anencefálicos também cederam espaço a entidades religiosas e teológicas e até mesmo a movimentos sociais feministas. Desse modo, os mecanismos de inclusão-participativa servem, tanto para contribuir para as capacidades institucionais da Corte ao decidir, quanto para preservar a legitimidade de sua atuação.

Os mecanismos institucionais dialógicos podem ser desenvolvidos de acordo com a experiência democrática conquistada em cada ordem constitucional. Dependendo das disposições constitucionalmente previstas e da tradição do comportamento de suas instituições, mecanismos distintos podem ser desenvolvidos. A concepção de instrumentos legitimadores da atividade da Corte Constitucional brasileira pode ser auxiliada através da observação dos 
experimentos realizados pela teoria constitucional e pela efetiva prática institucional norte-americana e canadense em suas vias de constrained judicial review.

Primeiramente, é preciso esclarecer que o debate sobre os diálogos institucionais não se restringe à relação entre Judiciário e Legislativo, mas este é o campo em que se encontram maiores propostas por parte das teorias. ${ }^{17}$ Os diálogos institucionais resumem-se como uma metáfora definidora do mecanismo de atuação das instituições quando suas decisões afetam diretamente deliberações construídas por outra instituição (LECLAIR, 2003). Remonta-se a ideia de que as instituições, em seu comportamento, precisam se ajustar à organização e às atribuições das demais, evitando colisões e atritos entre si que possam gerar alguma queda de legitimidade ou dificuldade, impasses no plano democrático ou complicações na concretização das normas constitucionais.

O debate canadense sobre as teorias dialógicas gira em torno da atuação de sua Suprema Corte e a efetivação dos direitos fundamentais da Carta Canadense. Rosalind Dixon elabora uma das teorias dos diálogos institucionais mais instigantes (DIXON, 2009). Preocupada com as relações entre o Judiciário e o Legislativo, formula um sistema de atuação no qual, ao invés de contrariar e suprimir as deliberações do Legislativo, o Judiciário deveria permitir que este lançasse um "segundo olhar" sobre a questão ${ }^{18}$. A partir de Dixon, é possível afirmar que a teoria canadense tem a preocupação de corrigir imperfeições no campo constitucional, mas fazê-lo sem grandes interferências em matérias reservadas a entes com papel próprio em uma estrutura com poderes distintos. A ideia do second look cases promovido pelo Legislativo, instituição que deliberou inicialmente a questão sub judice na Corte, caracteriza a teoria de Dixon como um padrão de comportamento institucional fundado no requerimento de autorreflexão sobre deliberações próprias, mantendo a Corte em aguardo de seu posicionamento, o que ela chama de narrow statement ex ante.

${ }^{17} \mathrm{O}$ debate acerca dos diálogos institucionais foi iniciado com (HOGG; BUSHELL, 1997). Nesta pesquisa, ainda havia uma limitação à relação entre Judiciário e Legislativo, pois seu objeto era precisamente a lógica das declarações de inconstitucionalidade da Suprema Corte Canadense. Posteriormente, suas discussões superaram os limites das declarações de inconstitucionalidade e da relação Judiciário-Legislativo.

18 "It may look as though the SCC is being asked to practice two different forms of review, but as the article explains, this approach to second look decision making should not be rejected out of a concern for judicial independence. Provided courts are mindful of its preconditions and rationale, such an approach will be fully compatible with the maintenance of judicial independence" (DIXON, 2009, p. 4). 
A teoria norte-americana, por outro lado, sob a perspectiva de Cass Sunstein, trata a questão diferentemente (SUNSTEIN, 1999). O minimalismo judicial seria uma teoria dialógica a partir do momento em que a Suprema Corte, nos momentos de promover o judicial review, considera suas capacidades institucionais e os resultados advindos sobre suas decisões a partir de suas deliberações. Segundo tal teoria dialógica, a atuação da Suprema Corte em decidir somente sobre os assuntos estritamente necessários, desenvolve sua atividade a partir de dois critérios: profundidade e amplitude. Para Sunstein, uma atuação da Corte que decide somente o que é essencial na questão, tendo um padrão de atuação shalow e narrow, alcança resultados positivos. Quando alguma questão deixa de ser decidida pela Corte, desde que não implique prejuízos aos cidadãos, a responsabilidade repousa nos agentes democraticamente legítimos sobre a decisão - o Legislativo. Chama-se a isto democracy-promote minimalism, um comportamento de caráter dialógico que alerta as instituições democraticamente responsáveis sobre deliberações que devem realizar.

Em uma análise comparativa, é possível afirmar que o debate canadense estrutura-se sobre problemas relativos à questão democrática, vis-à-vis a situação de legitimidade que se pretende preservar. $\mathrm{O}$ debate norte-americano centra-se na questão institucional, versando sobre capacidades e resultados sistêmicos. Em ambos os casos, são evitadas situações de tensão política e de desgaste da legitimidade da Corte Constitucional, preservando seu prestígio na ordem institucional e perante seus jurisdicionados. Embora a Corte Constitucional brasileira tenha apresentado alguns exemplos de comportamento contido em suas decisões, apesar dos episódios de ativismo judicial da última década, ainda não foram estabelecidos mecanismos regulares e de uso corrente de diálogo com as demais instituições atuantes em seu plano. Apenas em algumas ocasiões, o STF dialoga com outras autoridades por meio das próprias audiências públicas, como no julgamento dos casos de judicialização do direito à saúde, convocando membros do ministério correspondente, o que demonstra uma precariedade em seus mecanismos de diálogo institucional.

Analisando estas duas espécies de instrumentalização da legitimidade - mecanismos de inclusão-participativa e de diálogo institucional -, a saída para as imperfeições do sistema democrático não parece ser redefinir radicalmente toda a estrutura constitucional do Estado, mas usar o potencial de racionalidade de cada discussão aberta nas instituições, em respeito aos fundamentos constitucionais. Ao invés de buscar grandes reorganizações no desenho institucional em nível de grandes arranjos, talvez seja mais interessante 
elaborar mecanismos democráticos em uma escala mais reduzida que possam atender a valores como a deliberação (VERMEULE, 2011). A partir do momento que as limitações técnicas, econômicas ou políticas são reconhecidas, impedindo uma saída no molde das teorias de first-best, as perspectivas institucionais como a instrumentalização da legitimidade se apresentam como saídas estratégicas para a atividade deliberativa democrática da Corte Constitucional.

\section{CONCLUSÃO}

Considerando-se a necessidade de estabelecimento de parâmetros deliberativos bem definidos e compartilhados pelas instituições em um sistema dialógico e cooperativo de atividade, necessita-se de um procedimento democrático claro e definido para esta construção. Defende-se, aqui, que as Cortes Constitucionais podem exercer um papel de liderança no estabelecimento de tais parâmetros necessários à coordenação da atividade institucional.

Para justificar a presente hipótese, é preciso analisar quais são os procedimentos democráticos institucionalizados no âmbito de suas atividades de modo a compreender se estão sendo elaborados mecanismos democráticos capazes de suprir as falhas e as dificuldades dos arranjos de grande dimensão institucional. Neste sentido, entre uma série de críticas quanto à falta de capacidades institucionais e o grau de legitimidade da atividade das Cortes na atual conjuntura político-jurídica, é de central importância a criação e o aprimoramento do que chamamos de mecanismos de instrumentalização da legitimidade. Estes podem representar alternativas à deliberação democrática, amparando-se em, pelo menos, duas propostas para o caso das Cortes Constitucionais: (i) por meio de procedimentos inclusivo-participativos para cidadãos que, de alguma forma, podem contribuir à potencialização do debate, fornecendo informações que, a princípio, não são de domínio das Cortes implementando suas capacidades institucionais - ou diretamente envolvidos e afetados pelos efeitos da decisão - abrangendo a previsibilidade de seus efeitos sistêmicos; ou (ii) por meio de critérios ou princípios dialógicos de decisão que aproximem a Corte das entidades democraticamente responsáveis pela deliberação, reduzindo as proporções das críticas que apelam a um viés mais propriamente legitimatório.

Por meio de tais mecanismos institucionais em pequena escala, resultados significativos podem ser obtidos pela Corte Constitucional, contribuindo-se para sua atividade na definição de parâmetros deliberativos para a ordem constitucional. 


\section{REFERÊNCIAS}

BOHMAN, James. Public deliberation: pluralism, complexity and democracy. Cambridge, MA: MIT Press, 2000.

BOLONHA, Carlos; RANGEL, Henrique; ALMEIDA, Maíra. John Rawls e as Instituições Democráticas. Revista JurisPoeisis, Ano 13, n. 13, jan-dez, 2011.

BUENO, Cassio Scarpinella. Amicus curiae no processo civil brasileiro: um terceiro enigmático. 2. ed. São Paulo: Saraiva, 2008.

DIXON, Rosalind. The Supreme Court of Canada, Charter Dialogue, and Deference. Public Law and Legal Theory Working Papers Series, Chicago, n. 284, nov. 2009.

Weak-form Judicial Review and the American exceptionalism. Law School Public Law \& Legal Theory Working Papers Series, Chicago, n. 348, may 2011.

DWORKIN, Ronald. Taking Rights Seriously, Cambridge. MA: Harvard University Press, 1977.

FALCÃO, Joaquim; HARTMANN, Ivar; CHAVES, Vitor Pinto. III Relatório Supremo em Números: O Supremo e o Tempo. Rio de Janeiro, RJ: Escola de Direito do Rio de Janeiro da Fundação Getulio Vargas, 2014.

FAVOREU, Louis. As cortes constitucionais. Tradução de Dunia Marinho Silva. São Paulo, SP: Landy, 2004.

GOODIN, Robert (Ed.). The theory of institutional design. Cambridge, MA: Cambridge University Press, 1996.

GILlMAN, Howard; CLAYTON, Cornell. The Supreme Court in American politics: new institutionalist interpretation. Lawrence, KA: Kansas University Press, 1999. 
GRIFFIN, Stephen. American Constitutionalism: From Theory to Politics. Princeton, NJ: Princeton University Press, 1999.

. The Age of Marbury: Judicial Review in a Democracy of Rights. In: TUSHNET, Mark (Ed.). Arguing Marbury v. Madison. Stanford, CA: Stanford University Press, 2005.

HABERMAS, Jürgen. Between Facts and Norms: contributions to a Discourse Theory of Law and Democracy. Cambridge, MA: The MIT Press, 1996.

HOGG, Peter; BUSHELL, Allison. The Charter dialogue between Courts and Legislatures: or perhaps the Charter of Rights isn't such a bad thing after all. Osgoode Law Review, v. 35, n.1, p.75-124, Spring, 1997.

LECLAIR, Jean. Réflexions critiques au sujet de la métaphore du dialogue en droit constitutionnel canadien. Revue du Barreau du Québec, avril 2003. Disponivel em:<https://papyrus.bib.umontreal.ca/jspui/handle/1866/ 2549>. Acesso em: 8 abr. 2011.

LEVINSON, Daryl; PILDES, Richard. Separation of parties, not powers. Harvard Law Review, v. 119, n. 1, 2006.

LOWMAN, Michael. The litigating amicus curiae: when does the party begin after the friends leave?. American University Law Review, v.41, n.4, p. 1243-1299, 1992.

MARRILL, Thomas; KEARNEY, Joseph. Influence of amicus curiae briefs on the Supreme Court. University of Pennsylvania Law Review, v. 148, n. $743,2000$.

MEDINA, Damares. Amicus curiae - amigo da corte ou amigo da parte? São Paulo, SP: Saraiva Editora, 2010.

ROCHA, José de Albuquerque. Estudos sobre o Poder Judiciário. São Paulo, SP: Malheiros, 1995. 
SHINAR, Adam; HAREL, Alon. Between judicial and legislative supremacy: a cautious defense of constrained judicial review. 2011. Disponível em: <http://papers.ssrn.com/sol3/papers.cfm?abstract_id= 1760963>. Acesso em: 1 ago. 2011.

SUNSTEIN, Cass; VERMEULE, Adrian. Interpretation and institutions.

Public Law \& Legal Theory Working Papers Series, Chicago, n. 28, 2002.

SUNSTEIN, Cass. One case at a time: judicial minimalism in the Supreme Court. Cambridge, MA: Harvard University Press, 1999.

THAYER, James. The origin and scope of the American doctrine of Constitutional Law. Harvard Law Review, v. 7, n.129, 1893.

TUSHNET, Mark. Popular constitutionalism as political law. Chicago-Kent Law Review, v. 81, n. 991, 2006.

. Weak Courts, Strong Rights: Judicial Review and Social Welfare Rights in Comparative Constitutional Law. Princeton, NJ: Princeton University Press, 2007.

VERMEULE, Adrian. Mechanisms of democracy: institutional design writ small. New York, NY: Oxford University Press, 2011.

WILLIAM, Nelson. Marbury v. Madison: the origins and legacy of Judicial Review. Lawrence, KA: The University Press of Kansa, 2000.

Artigo recebido em: 26/10/2014 Aprovado para publicação em: 22/04/2015

Como citar: RANGEL, Henrique. BOLONHA, Carlos. SEPULVEDA, Antonio. Cortes constitucionais e instrumentalização da legitimidade. Revista do Direito Público. Londrina, v.10, n.1, p.171-187, jan./abr.2015. DOI: 10.5433/1980-511X.2015v10n1p171. 